\title{
A Testis-Specific Long Non-Coding RNA, IncRNA-Tcam1, Regulates Immune-Related Genes in Mouse Male Germ Cells
}

\author{
Misuzu Kurihara' ${ }^{1 \dagger}$, Kai Otsuka ${ }^{1}$, Shin Matsubara ${ }^{2}$, Akira Shiraishi ${ }^{2}$, Honoo Satake ${ }^{2}$ and \\ Atsushi P. Kimura ${ }^{1,3 *}$ \\ ${ }^{1}$ Graduate School of Life Science, Hokkaido University, Sapporo, Japan, ${ }^{2}$ Bioorganic Research Institute, Suntory Foundation \\ for Life Sciences, Kyoto, Japan, ${ }^{3}$ Department of Biological Sciences, Faculty of Science, Hokkaido University, Sapporo, \\ Japan
}

\section{OPEN ACCESS}

Edited by:

Takayoshi Ubuka,

Monash University Malaysia,

Malaysia

Reviewed by:

Takashi Yazawa,

Asahikawa Medical College,

Japan

Satyanarayana M. R. Rao,

Jawaharlal Nehru Center for

Advanced Scientific Research,

India

${ }^{*}$ Correspondence:

Atsushi P. Kimura

akimura@sci.hokudai.ac.jp

${ }^{\dagger}$ Present address: Misuzu Kurihara, Division of Nuclear Dynamics, Okazaki Institute for Integrative Biosciences, Okazaki, Japan

Specialty section: This article was submitted to Experimental Endocrinology, a section of the journa

Frontiers in Endocrinology

Received: 01 September 2017 Accepted: 16 October 2017 Published: 02 November 2017

Citation:

Kurihara M, Otsuka K, Matsubara S, Shiraishi A, Satake $H$ and Kimura AP (2017) A Testis-Specific Long Non-Coding RNA, IncRNA-Tcam1, Regulates Immune-Related Genes in Mouse Male Germ Cells.

Front. Endocrinol. 8:299. doi: 10.3389/fendo.2017.00299
Spermatogenesis is precisely controlled by hormones from the hypothalamus-pituitarygonadal axis and testis-specific genes, but the regulatory mechanism is not fully understood. Recently, a large number of long non-coding RNAs (IncRNAs) are found to be transcribed at each stage of meiosis of male germ cells, and their functions in spermatogenesis have yet to be fully investigated. IncRNA-testicular cell adhesion molecule 1 (IncRNA-Tcam1) is a nuclear IncRNA which is specifically expressed in mouse male germ cells and presumed to play a role in gene regulation during meiosis. Here, we present the identification of potential target genes of IncRNA-Tcam1 using spermatocyte-derived GC-2spd(ts) cells. Initially, 55 target gene candidates were detected by RNA-sequencing of two GC-2spd(ts) cell clones that were stably transfected with transgenes to express IncRNA-Tcam 1 at different levels. Expression of 21 genes of the candidates was found to be correlated with IncRNA-Tcam1 at 7-14 postnatal days, when IncRNA-Tcam1 expression was elevated. Subsequently, we examined expression levels of the 21 genes in other two GC-2spd(ts) clones, and 11 genes exhibited the correlation with IncRNATcam1. Induction of IncRNA-Tcam 1 transcription using the Tet-off system verified that six genes, Trim30a, Ifit3, Tgtp2, Ifi47, Oas1g, and Gbp3, were upregulated in GC-2spd(ts) cells, indicating that IncRNA-Tcam 1 is responsible for the regulation of gene expression of the six genes. In addition, five of the six genes, namely, Ifit3, Tgtp2, Ifi47, Oas1g, and Gbp3, are immune response genes, and Trim30a is a negative regulator of immune response. Altogether, the present study suggests that IncRNA-Tcam 1 is responsible for gene regulation for the immune response during spermatogenesis.

\section{Keywords: long non-coding RNA, spermatogenesis, GC-2spd(ts) cells, gene activation, immune response}

\section{INTRODUCTION}

Spermatogenesis is a process to generate spermatozoa, composed of meiosis and spermiogenesis $(1,2)$. In meiosis, some population of spermatogonia differentiate into spermatids, and the spermatids change their shapes to become spermatozoa through spermiogenesis. This process is controlled by the hypothalamus-pituitary-gonadal axis. The pituitary secretes gonadotropin in response to gonadotropin releasing hormone from hypothalamus, by which steroid production is stimulated in testis, leading to normal progression of spermatogenesis (3-5). In addition, many testis-specific 
genes are activated in germ cells during meiosis and play important roles in spermatogenesis (6-14). However, the regulatory mechanism of spermatogenesis is not fully understood. To date, various long non-coding RNAs (lncRNAs) have been identified in the testis $(15,16)$, and some of them were shown to be upregulated by sex steroids (17-21). These findings suggest that lncRNAs are involved in the regulation of spermatogenesis. Nevertheless, the physiological significance of lncRNAs and the molecular mechanisms of their actions in the testis are largely unknown.

Long non-coding RNAs are molecules that are longer than 200 nucleotides and function without being translated (22). They are localized in nuclei, cytosols, and extracellular vesicles (23-25), and involved in various biological events such as development $(26,27)$, cell differentiation $(28,29)$, immune response $(30,31)$, and cell metabolism $(32,33)$. lncRNAs exert their effects via controlling gene expression at various levels, i.e., transcription, mRNA stability, and translation $(22,26,34)$. In nuclei, lncRNAs are frequently involved in the transcriptional control of proteincoding genes (35). Thus, lncRNAs are presumed to be essential for transcriptional regulation of meiotic genes during spermatogenesis, while biological functions of testicular lncRNAs have not been well investigated.

We have studied the mechanism of gene activation during meiosis by using the mouse testicular cell adhesion molecule 1 (Tcam1) locus as a model. The Tcam 1 gene is specifically expressed in spermatocytes and encodes a cell adhesion molecule, which is dispensable for sperm generation $(36,37)$. We previously identified a dual promoter-enhancer, which enhanced the Tcam 1 gene transcription and drove the SWI/SNF-related, matrix-associated, actin-dependent regulator of chromatin, subfamily $d$, member 2 (Smarcd2) gene and IncRNA-Tcam1 (38). IncRNA-Tcam1 was a novel testis-specific lncRNA which was $2.4-\mathrm{kb}$ nucleotide long and localized to nuclei of germ cells but not to Leydig and Sertoli cells (38). Such germ cell-specific localization suggests that IncRNA-Tcam 1 plays a role in specific gene activation during meiosis.

To study molecular mechanisms in various types of cells, the in vitro cell culture system is useful, and some cell lines were established from male germ cells (39). The GC-2spd(ts) cell line was established from mouse spermatocytes using the SV40 large $\mathrm{T}$ antigen and the temperature-sensitive P53 mutant gene (40), and was widely used due to their ability of differentiation. After multiple cell passages, the cells still maintain some properties as male germ cells and are widely used for examining mechanisms in germ cells (41-48). Thus, the GC-2spd(ts) cell line is one of the most useful models for the study of the regulatory mechanism in male germ cells.

In this paper, we show that $\operatorname{lncRNA-Tcam} 1$ induces immunerelated genes in GC-2spd(ts) cells, which shed new light on novel regulatory roles of lncRNAs in the testis.

\section{MATERIALS AND METHODS}

\section{Animals}

The mice (C57/BL6) were maintained at $25^{\circ} \mathrm{C}$ with a photoperiod of 14:10 h light:dark with free access to food and water. Testes were isolated from 7 - to 56 -day-old mice and stored at $-80^{\circ} \mathrm{C}$ until use. Experimental procedures used in this study were approved by the Institutional Animal Use and Care Committee at Hokkaido University.

\section{Cell Culture}

GC-2spd(ts) and its derivatives were cultured in Dulbecco Modified Eagle medium containing 10\% fetal bovine serum, $100 \mathrm{U} / \mathrm{ml} \mathrm{penicillin,} 100 \mu \mathrm{g} / \mathrm{ml}$ streptomycin, and $292 \mu \mathrm{g} /$ $\mathrm{ml} \mathrm{L-glutamine} \mathrm{(Invitrogen,} \mathrm{Carlsbad,} \mathrm{CA,} \mathrm{USA)}(38,40)$. We used two types of GC-2spd(ts)-derived cell clones: IncRNA6.9kb-EGFP clones that contained the intact sequence of the lncRNA-Tcam 1 locus (full sequence) and $\Delta$ CNS1-lncRNA-EGFP clones that lacked the $\operatorname{lncRNA-Tcam1}$ promoter ( $\Delta$ promoter) (Figure 1A).

\section{RNA Preparation and Quantitative Reverse Transcription-Polymerase Chain Reaction (qRT-PCR)}

Isolation of total RNAs, treatment with DNase, and qRT-PCR were done as previously described $(38,49)$. To detect $\operatorname{lncRNA-}$ Tcam1, we used KOD SYBR qPCR Mix (Toyobo, Osaka, Japan), and the other transcripts were measured with Power SYBR Green Master Mix (Applied Biosystems, Foster City, CA, USA). Primer pairs are listed in Table $\mathbf{1 .}$

\section{RNA-Sequencing (RNA-seq) Analysis}

Total RNAs were isolated from a lncRNA-6.9kb-EGFP clone (full sequence) and a $\Delta$ CNS1-lncRNA-EGFP clone ( $\Delta$ promoter) using ISOGEN II (Nippongene, Tokyo, Japan) according to the manufacturer's instruction. The RNAs were further purified by phenol/chloroform-isoamylalcohol extraction and ethanol precipitation, and treated with TurboDNase (Applied Biosystems). The quality of the RNA samples was evaluated using BioAnalyzer (Agilent Technologies, Palo Alto, CA, USA) with RNA6000 Nano Chip. A 500-ng aliquot of total RNA from each sample was used to construct cDNA libraries using TruSeq Stranded mRNA Sample preparation kit (Illumina, San Diego, CA, USA), according to the manufacturer's instructions. The resulting cDNA library was validated using BioAnalyzer with DNA1000 Chip and quantified using Cycleave PCR Quantification Kit (Takara Bio Inc., Otsu, Japan). 101-cycle of single-end sequencing was performed using HiSeq1500 (Illumina) in the rapid mode. Total reads were extracted with CASAVA v1.8.2 (Illumina). Then, PCR duplicates, adaptor sequences and low quality reads were removed from the extracted reads as follows. Briefly, if the first 10 bases of the two reads were identical and the entire reads exhibited $>90 \%$ similarity, the reads were considered PCR duplicates. Remaining reads were then aligned with Bowtie version 2.2.3 to the mouse genome, $\mathrm{mm} 10$, which was downloaded from UCSC (https://genome.ucsc.edu/). The expression level of each gene was calculated as gene-specific reads per million total reads (RPM).

\section{Plasmid Construction}

A PiggyBac-based plasmid for induction of $\operatorname{lncRNA-Tcam} 1$ transcription was generated as follows. A full length of $\operatorname{lncRNA-Tcam1}$ 


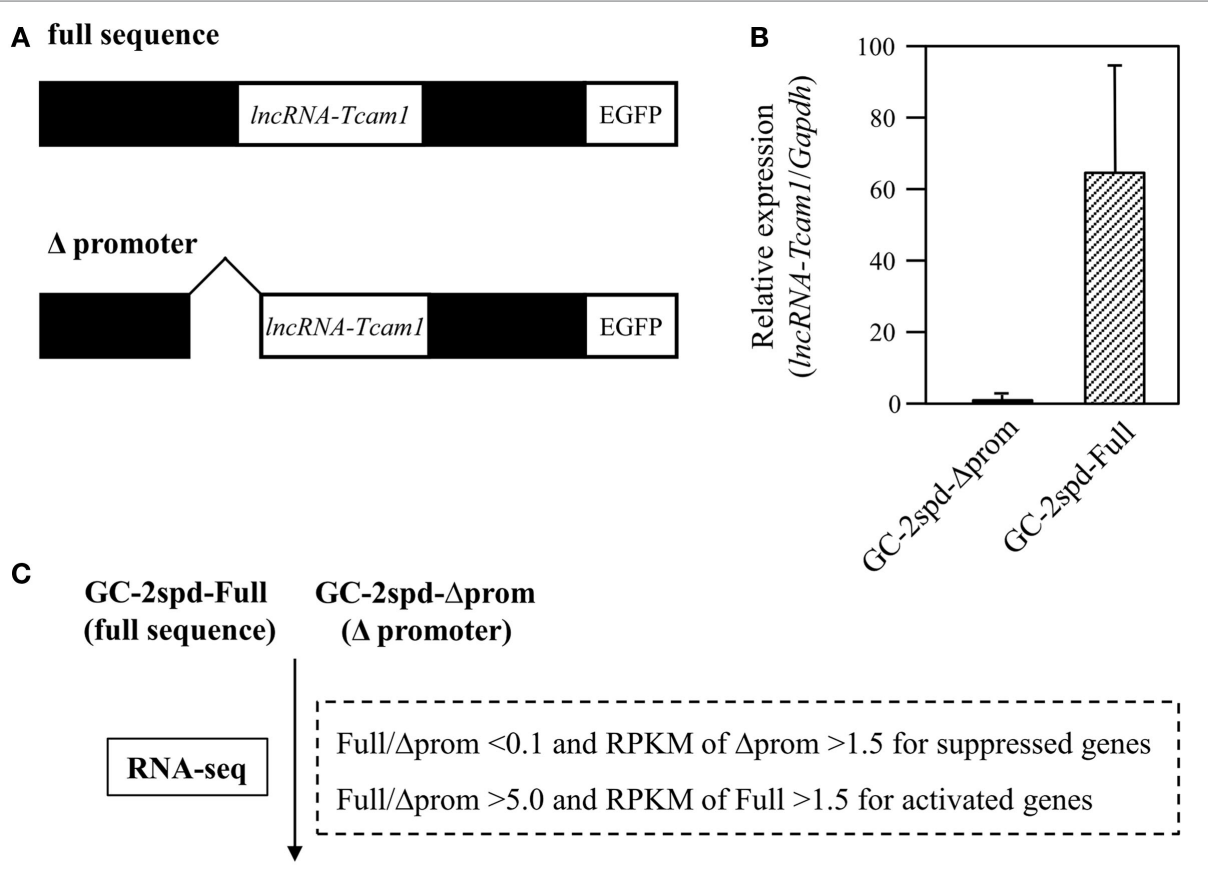

55 genes (suppressed: 29 genes, activated: 26 genes)

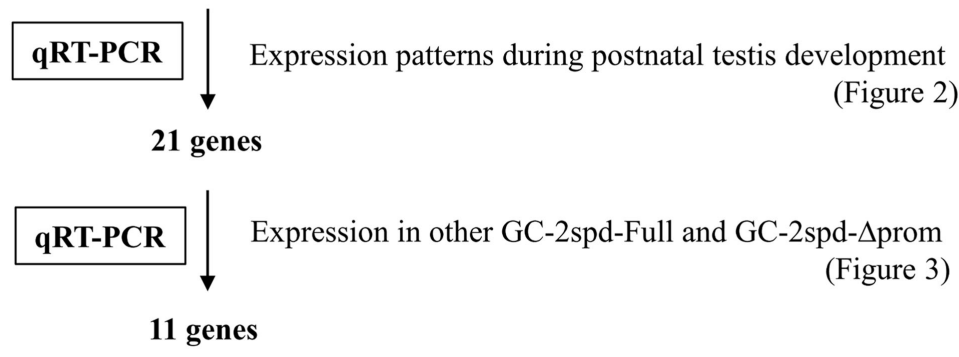

\begin{tabular}{|l|} 
qRT-PCR \\
Expression on the induction of $\ln C R N A-T c a m 1$ transcription \\
(Figure 4)
\end{tabular}

6 genes (5 immune response genes)

FIGURE 1 | A strategy to identify potential target genes of long non-coding RNA-testicular cell adhesion molecule 1 (IncRNA-Tcam1). (A) Constructs used for establishing GC-2spd(ts) cell clones that expressed IncRNA-Tcam1 at different levels. A 6.9-kb sequence encompassing the upstream and downstream regions of IncRNA-Tcam1 was obtained from a mouse BAC clone, and connected to the enhanced green fluorescent protein (EGFP) gene (full sequence). A 0.8-kb sequence corresponding to the IncRNA-Tcam1 promoter was deleted by restriction digestion ( $\triangle$ promoter). The reporter EGFP gene was used to investigate the transcriptional regulation activity of the IncRNA promoter sequence in our previous study. Each construct was transfected into GC-2spd(ts) cells, and stable cell clones were established by the limited dilution method. (B) Expression of IncRNA-Tcam1 in GC-2spd-Full and GC-2spd- $\Delta$ prom. GC-2spd- $\Delta$ prom was derived from the cells transfected with " $\Delta$ promoter" and used as a clone expressing IncRNA-Tcam1 at a low level. GC-2spd-Full was a stably transfected clone with "full sequence" and used as the cells expressing IncRNA-Tcam1 at a high level. Total RNA was isolated from each clone, and the expression level of IncRNA-Tcam1 was measured by quantitative reverse transcription-polymerase chain reaction (qRT-PCR). The value was normalized to the Gapdh mRNA level, and the level in GC-2spd- $\Delta$ prom was set to 1.0. The data are presented as mean value \pm SD from three independent experiments. (C) An outline of the screening process to identify potential target genes of IncRNA-Tcam1 in this study.

was amplified by PCR with mouse genome DNA and KOD FX Neo (Toyobo) using a primer pair, 5' -CCGGAGGAGCGGGAG CGGAA-3' and 5' -CACCGGAAAACAGCTTTAAT-3' . We used

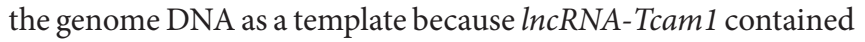
no intron. The product was subcloned into a pBluescript II vector (Stratagene, La Jolla, CA, USA) at EcoRV site, and the resulting plasmid was checked by DNA sequencing method. This plasmid was digested with SalI, blunted by T4 DNA polymerase (Takara), and further digested with NotI. The IncRNA-Tcam 1 fragment was purified and inserted into $\mathrm{pBhCMV}^{\star} 1-\mathrm{cHA}-\mathrm{pPA}$ at the NotI/blunted XhoI site. The completed plasmid was checked by DNA sequencing and named pPBhCMV ${ }^{\star} 1$-lncTcam1-pPA. All plasmids for establishing the Tet-off system were kindly gifted by Dr. Kazuhiro Murakami (50). 
TABLE 1 | Oligonucleotide primers used in this study.

\begin{tabular}{|c|c|c|}
\hline Designation & Forward & Reverse \\
\hline IncRNA-Tcam 1 & 5'-GACTGTCTGGGCAGAGTGAA-3' & 5'-GAACCCAAGCAAAGCTGTAAAC-3' \\
\hline Aip & 5'-GAGGACGGGATCCAAAAGC-3' & 5'-CTGTGCAGCGTCCGAAAGT-3' \\
\hline Gapdh & 5'-TGCACCACCAACTGCTTAGC-3' & 5'-GGCATGGACTGTGGTCATGAG-3' \\
\hline $\mathrm{H} 19$ & 5'-TGGGAAAAGTGAAAGAACAG-3' & 5'-GTGTGATGGAGAGGACAGAA-3' \\
\hline Ren1 & 5'-ATCCTITATCTCGGCTCCTA-3' & 5'-ACCTGGCTACAGTTCACAAC-3' \\
\hline lgfbp5 & 5'-CTGACССТСТАССТTССТП-3' & 5'-TGAGCAGACTICTTGGTा-3' \\
\hline Gpx7 & 5'-GTTCACCACCAGGGAAAC-3' & 5'-GCAGGACTTCTACGACTTCA-3' \\
\hline Bmyc & 5'-GACCACGACGGTGATAGCTT-3' & 5'-TCCAGCTTGGAGACCAGCTT-3' \\
\hline Avpr1a & 5'-AAGATCCGCACAGTGAAGAT-3' & 5'-GTTCAAGGAAGCCAGTAACG-3' \\
\hline ligp1 & 5'-AAGAGCACACCGAGGGCTAT-3' & 5'-GCTGGAGGGCAAATCATTAT-3' \\
\hline Oas2 & 5'-CTACTGACCCAGATCCAGAA-3' & 5'-TGGCACTITCCAAGGCTGTA-3' \\
\hline Trim30a & 5'-GGACAGGTTACTTCCTCCTT-3' & 5'-GTCTCTTGGTTGGTATCTGA-3' \\
\hline Ifit3 & 5'-CCAGCAGCACAGAAACAGAT-3' & 5'-GACATACTTCCTTCCCTGAA-3' \\
\hline Hoxd13 & 5'-GGAACAGCCAGGTGTACTGT-3' & 5'-TCATTCTCCAGTTCTाTGAG-3' \\
\hline Tgtp2 & 5'-ATGGCTCTGTATGGTAGAAG-3' & 5'-CAGAACTCCACACCTCATGT-3' \\
\hline Mx2 & 5'-TTCAAGGAACACCСТCATT-3' & 5'-CTCTGCGGTCAGTCTCTCT-3' \\
\hline Fabp5 & 5'-ACGGGAAGGAGAGCACGATA-3' & 5'-GCAGGTGGCATTGTTCAT-3' \\
\hline Ifi47 & 5'-GTGAGAAACAGACCCGGTAT-3' & 5'-ATGCCTCCTGCCTTACTGAT-3' \\
\hline Enpp5 & 5'-CCTTGTTCTGCCTCCTCTT-3' & 5'-AGCCGAATGGCATAGAGTAG-3' \\
\hline Oas1g & 5'-CCAGATGAGGATGGTGTAGA-3' & 5'-TCAGGAGGTGGAGTITGAT-3' \\
\hline Usp18 & 5'-CTCGGTGATACCAAGGAACA-3' & 5'-ACCAAAGTCAGCCATCCCAA-3' \\
\hline Gbp3 & 5'-GGATTCTTGAGCAGATAGCA-3' & 5'-ATACCCTTGGTITCGGATT-3' \\
\hline Ifi44 & 5'-GGTTGATGTGATTGGTTC-3' & 5'-CTGCCATITATTCTGTGTGA-3' \\
\hline Ifit1 & 5'-GAGTTCTGCTCTGCTGAAAA-3' & 5'-AGGAACTGGACCTGCTCTGA-3' \\
\hline
\end{tabular}

\section{Establishment of the Tet-Off System and Induction of IncRNA-Tcam1 Transcription}

GC-2spd(ts) cells were co-transfected with $\mathrm{pPBhCMV}^{\star} 1$-lncTcam1-pPA, pPBCAGtTA-IN, pPyCAG-PBase, and pKO-SelectPuro plasmids using GeneJuice transfection reagent (Merck, Darmstadt, Germany) and selected with $3 \mu \mathrm{g} / \mathrm{ml}$ puromycin for 14 days. The selected cells were kept in the presence of $1 \mu \mathrm{g} / \mathrm{ml}$ doxycycline (Dox). For inducing $\ln c R N A$-Tcam 1 transcription, the cells were spread onto $35-\mathrm{mm}$ dishes, and Dox was removed on the next day.

\section{Statistical Analysis}

The results were expressed as means $\pm \mathrm{SD}$. The data were analyzed by one-way analysis of variance (ANOVA) followed by Dunnett's test (Figures 2A, and 3B,C) or by Student's $t$-test (Figures 2B,C, 3A, and 4B) using Microsoft Excel statistical analysis functions (Microsoft Corporation, Redmond, WA, USA).

\section{RESULTS}

\section{RNA-seq with GC-2spd(ts) Cell Clones Expressing IncRNA-Tcam1 at Different Levels}

To identify potential target genes that were regulated by IncRNA-Tcam 1, we used GC-2spd(ts) cell clones we established in a previous study (38). In these lines, we stably transfected a construct, which contained a 6.9-kb sequence encompassing the Tcam 1 promoter and the $\operatorname{lncRNA-Tcam} 1$ region (full sequence) or the same sequence without the IncRNA-Tcam 1 promoter $(\Delta$ promoter $)$, connected to the enhanced green fluorescent protein (EGFP) gene (Figure 1A). $\ln c R N A-T c a m 1$ was expressed at higher levels in the clones with "full sequence" than those with " $\Delta$ promoter" (38), and hereafter, we designated "GC-2spd-Full" and "GC-2spd- $\Delta$ prom," respectively. We chose a representative cell clone from each cell line, and the GC-2spd-Full and GC-2spd- $\Delta$ prom clones showed 63-fold difference in expression

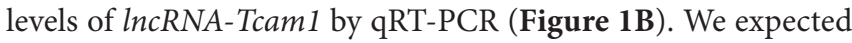
that target genes of this lncRNA should be expressed at different levels between them.

To determine the genes that were differentially expressed between GC-2spd-Full and GC-2spd- $\Delta$ prom, we performed the RNA-seq analysis. 101-cycle of single-end sequencing using HiSeq 1500 yielded 13,054,029 and 13,194,037 reads for GC-2spd-Full and GC-2spd- $\Delta$ prom, respectively, and 92.25 and $90.23 \%$ each of which was mapped to the mouse genome (mm10). The resultant fastq files were deposited on NCBI SRA database (accession no. SRR5435658 and SRR5435659). Subsequently, we compared the gene expression levels between GC-2spd-Full and GC-2spd- $\Delta$ prom, and picked proteincoding genes that were expressed at lower levels than 0.1 -fold in GC-2spd-Full as candidate genes negatively regulated by IncRNA-Tcam1, and those expressed at higher levels than fivefold in GC-2spd-Full as positively regulated genes. We then selected the gene whose RPKM value was higher than 1.5 in GC-2spd- $\Delta$ prom or GC-2spd-Full. As a result, 29 genes were

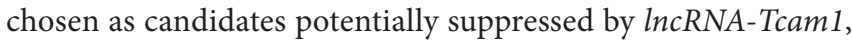
and 27 genes as those activated by the lncRNA. However, after this selection, we found that one potentially activated gene was 

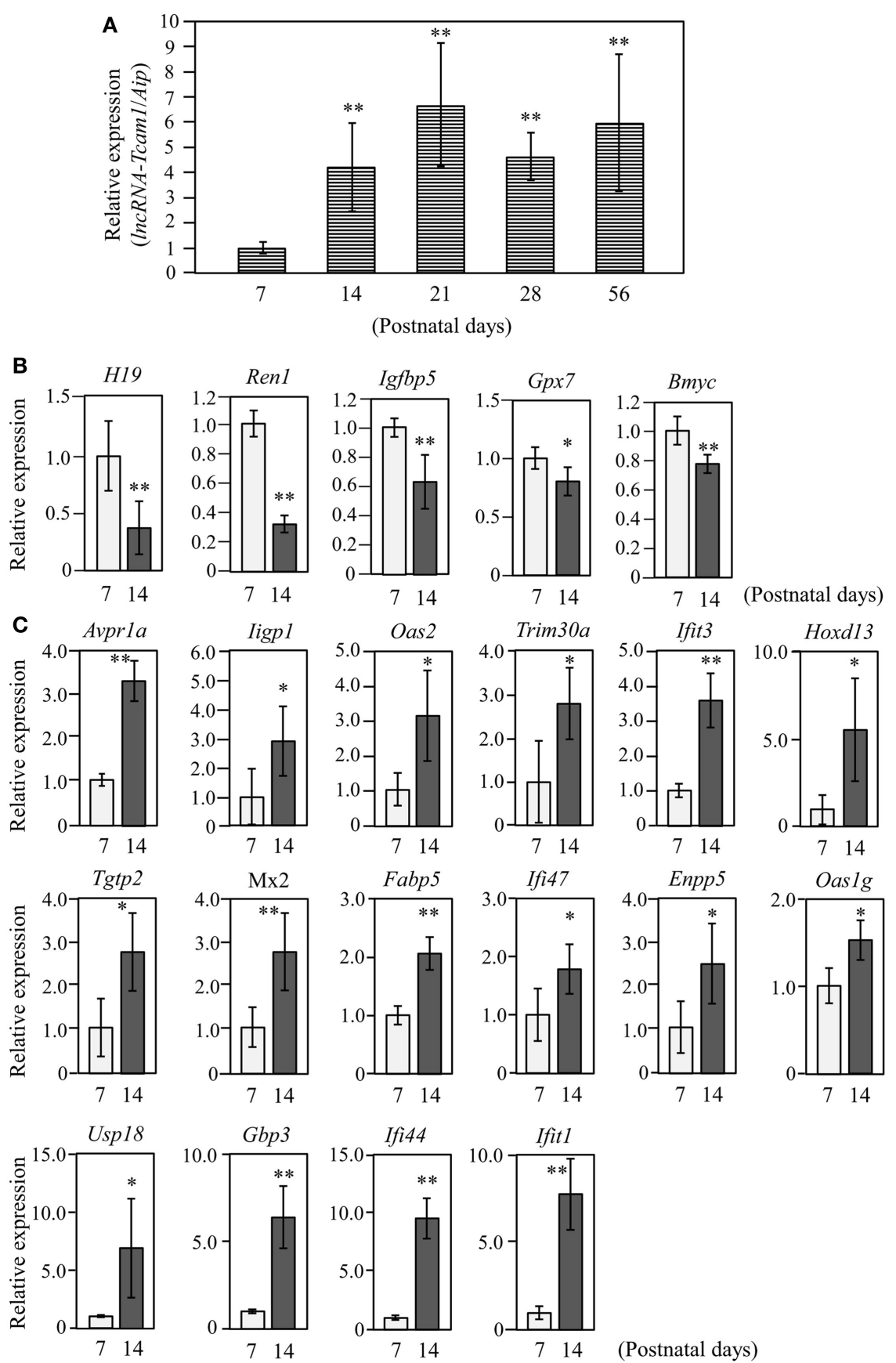

(Postnatal days)

FIGURE 2 | Expression of long non-coding RNA-testicular cell adhesion molecule 1 (IncRNA-Tcam1) and its target gene candidates in postnatal testes.

(A) IncRNA-Tcam 1 expression in mouse testes at various postnatal stages. Total RNAs were purified from whole testes of mice at indicated ages. Expression levels of IncRNA-Tcam1 were measured by quantitative reverse transcription-polymerase chain reaction (qRT-PCR) as in Figure 1B, and the data were normalized to the housekeeping Aip gene. The value at day 7 was set to 1.0. (B) Expression of five candidate genes that were presumed to be suppressed by IncRNA-Tcam 1 in testes of 7- and 14-day-old mice. qRT-PCR was performed, and the data were normalized to Aip. The level at day 7 was set to 1.0 . Light gray bars represent expression levels at 7 days of age, and light black bars indicate those at 14 days. (C) Expression of 16 candidate genes that were presumed to be activated by IncRNA-Tcam1. qRT-PCR was performed and the data were normalized as in (B). All experiments were performed four times with two different RNA sets from testes, and the averages \pm SD are indicated. The statistical significance was analyzed by one-way analysis of variance followed by Dunnett's test in (A) and by Student's $t$-test in $(\mathbf{B}, \mathbf{C}) .{ }^{\star} P<0.05,{ }^{*} P<0.01$ compared to day 7 .

not detected in GC-2spd-Full by qRT-PCR, and eliminated it from candidate genes. Consequently, a total of 55 genes $(29$ potentially suppressed and 26 activated genes, Tables S1 and
S2 in Supplementary Material) were subject to further analysis. An outline of the screening of candidate genes is shown in Figure 1C. 

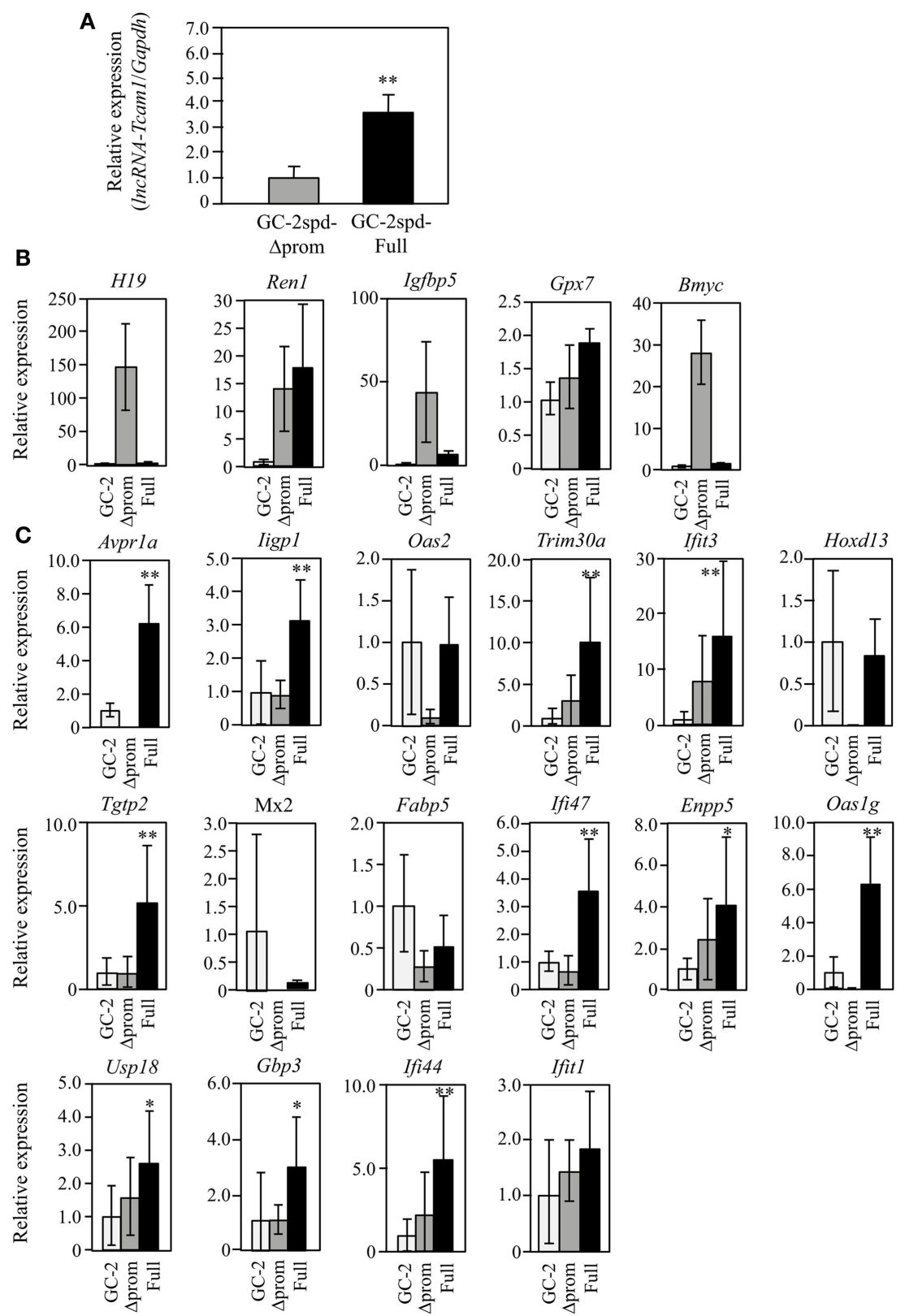

FIGURE 3 | Expression of IncRNA-testicular cell adhesion molecule 1 (IncRNA-Tcam1) and its target gene candidates in GC-2spd-Full and GC-2spd- $\Delta$ prom different from those used for RNA-sequencing. (A) IncRNA-Tcam1 expression in GC-2spd-Full and GC-2spd- $\Delta$ prom. The expression level of IncRNA-Tcam1 was measured by quantitative reverse transcription-polymerase chain reaction (qRT-PCR), and the data were normalized to Gapdh. The level in GC-2spd- $\Delta$ prom was set to 1.0. The data are the means \pm SD from three independent experiments, and the statistical significance was evaluated by Student's $t$-test. ${ }^{\star \star} P<0.01$ compared to GC-2spd- $\Delta$ prom. (B) Expression of five candidate genes that were presumed to be suppressed by IncRNA-Tcam1 in GC-2spd(ts) cells without being transfected, GC-2spd- $\Delta$ prom, and GC-2spd-Full. qRT-PCR was performed, and the data were normalized to Gapdh. The level in GC-2spd(ts) cells was set to 1.0. White bars represent the data from GC-2spd(ts) cells without transfection, and gray and black bars show the values from GC-2spd- $\Delta$ prom and GC-2spd-Full, respectively. (C) Expression of 16 candidate genes that were presumed to be activated by IncRNA-Tcam1. qRT-PCR was performed, and the data were normalized to Gapdh. The data are presented as in (B). The data for GC-2spd(ts) cells are the averages \pm SD from four independent experiments, and the other data represent the means \pm SD from three independent experiments. The statistical significance was evaluated by one-way analysis of variance followed by Dunnett's test in (B,C). ${ }^{\star} P<0.05,{ }^{\star \star} P<0.01$ compared to GC-2spd(ts) cells without transfection

\section{Expression of Candidate Genes in Postnatal Testes}

The target genes should be expressed correlatively to IncRNATcam 1 in the testis. We thus examined the expression of these potential target genes during postnatal testis development. We collected testes at 7-56 days after birth and measured the $\operatorname{lnc} R N A$ Tcam 1 level by qRT-PCR. The transcript of $\operatorname{lncRNA-Tcam1\text {was}}$ detected in all samples, and a significant increase was observed 
between day 7 and day 14 after birth (Figure 2A). The absence of $\operatorname{lncRNA-Tcam} 1$ expression in somatic cells in the mouse testis (38)

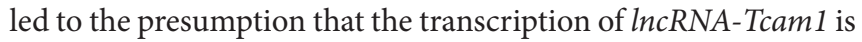
initiated in spermatogonia and increased in primary spermatocytes. Then, we examined expression levels of the 55 candidate genes ( 29 potentially downregulated and 26 upregulated) in the testis at 7 days and 14 days after birth by qRT-PCR, to compare their levels in spermatogonia and primary spermatocytes. Among the genes that might be suppressed by $\operatorname{lncRNA-Tcam1,5\text {genes}}$ showed significant decreases during this period (Figure 2B), and 16 genes out of potentially activated candidates exhibited significant increases (Figure 2C). The expression patterns of genes that were not correlated with $\operatorname{lncRNA-Tcam1}$ is presented in Figures S1 and S2 in Supplementary Material. Signals for four downregulated candidates, Cyclin D2 (Ccnd2), CD55 molecule, decay accelerating factor for complement (Cd55), Syndecan 3 (Sdc3), and uc009oek.1, and an upregulated candidate, $2^{\prime}-5^{\prime}$ oligoadenylate synthetase 3 (Oas3), were not detected by this analysis. From these data, 21 genes (5 genes down and 16 genes up) correlated with in vivo $\operatorname{lncRNA-Tcam} 1$ expression were forwarded to the next analysis as target gene candidates.

\section{Expression of Candidate Genes in GC-2spd(ts) Cell Clones Different from Those Used for RNA-seq}

To further validate the RNA-seq and postnatal testis data, the expression was also examined using GC-2spd(ts) clones that were different from those used for RNA-seq. This would help us to select the real targets, because the properties might be different between cell clones as a result of the process to establish stable cells and pick the clones. qRT-PCR demonstrated that $\ln$ RNA-Tcam 1 was expressed at a 3.5-fold higher level in GC-2spd-Full than in GC-2spd- $\Delta$ prom (Figure 3A). We assessed the expression of 21 candidate genes using these two clones and GC-2spd(ts) cells without being transfected. By comparing to cells without being transfected, false-positive genes (due to the establishment of cell clones) could be excluded. Among five genes potentially sup-

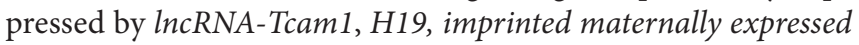
transcript (H19), Insulin-like growth factor binding protein 5 (Igfbp5), and Brain expressed myelocytomatosis oncogene (Bmyc) were expressed at much higher levels in GC-2spd- $\Delta$ prom than in GC-2spd-Full, but they were expressed at very low levels in GC-2spd(ts) cells without transfection (Figure 3B), indicating that these three genes were artifacts. Expression of Renin 1 structural (Ren1) and Glutathione peroxidase 7 (Gpx7) genes was positively correlated with IncRNA-Tcam1 (Figure 3B), which was inconsistent with the genes suppressed by $\operatorname{lncRNA-}$ Tcam1. Therefore, the five genes were unlikely to be targets of lncRNA-Tcam1.

Among 16 genes, expression levels of five genes $\left[2^{\prime}-5^{\prime}\right.$ oligoadenylate synthetase 2 (Oas2), Homeobox D13 (Hoxd13), MX dynamin-like GTPase 2 (Mx2), Fatty acid binding protein 5, epidermal (Fabp5), and Interferon-induced protein wit tetratricopeptide repeats 1 (Ifit1)] were not significantly higher in GC-2spd-Full than in GC-2spd(ts) cells (Figure 3C), excluding the possibility

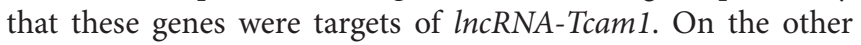

hand, 11 genes were expressed at significantly higher levels in GC-2spd-Full than in GC-2spd(ts) cells, and their expression was higher in GC-2spd-Full than in GC-2spd- $\Delta$ prom (Figure 3C). Collectively, these expression profiles detected 11 potential genes

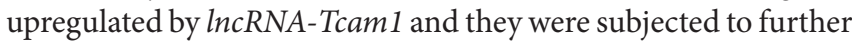
analysis.

\section{Identification of Genes Upregulated by IncRNA-Tcam1}

We finally examined whether $\ln R$ RNA-Tcam 1 could activate the 11 candidate genes in the Tet-off system. We constructed the plasmid in which the $\mathrm{hCMV}^{\star} 1$ promoter induced $\ln c R N A$ Tcam 1 transcription in response to the Dox removal, and stably transfected GC-2spd(ts) cells with it. qRT-PCR of the stable transfectants confirmed that the expression of $\operatorname{lncRNA-Tcam} 1$ was 57 -fold induced exclusively at $48 \mathrm{~h}$ after removal of Dox (Figure 4A).

We examined expression levels of the 11 candidate genes $48 \mathrm{~h}$ after the Dox removal by qRT-PCR. We set the value from the control cells that were cultured for $48 \mathrm{~h}$ with Dox to 1.0 and calculated the levels of candidates. six genes, Tripartite motif-containing 30A (Trim30a), Interferon-induced protein wit tetratricopeptide repeats 3 (Ifit3), T cell-specific GTPase 2 (Tgtp2), Interferon gamma inducible protein 47 (Ifi47), 2' -5' oligoadenylate synthetase $1 G$ (Oas1g), and Guanylate binding protein 3 (Gbp3), exhibited significantly higher expression in the cells without Dox, and their fold-increases were 1.46, 3.37, 2.43, 1.44, 1.49, and 1.69, respectively (Figure 4B). We confirmed significant levels of expression of the six genes in the germ cell fraction from adult mouse testes (Table S3 in Supplementary Material). Interestingly, five genes of the final six candidates, namely, Ifit3, Tgtp2, Ifi47, Oas1g, and Gbp3, were immune response genes, and Trim30a was a negative-feedback regulator of immune response (Table 2). Collectively, these data indicated that $\ln R$ RA-Tcam 1 is responsible for the regulation of some immune response pathways during spermatogenesis.

\section{DISCUSSION}

Among various mouse and human tissues, the testis contains large numbers of lncRNAs $(15,16)$, as evidenced by recent transcriptomic analyses identifying many lncRNAs in different postnatal testes or fractionated germ cells (51-53). However, their functions in spermatogenesis are largely unknown in mammals, and we revealed the upregulation of gene expression of immunerelated genes by mouse male germ cell-specific $\ln R$ RNA-Tcam 1 using spermatocyte-derived GC-2spd(ts) cells as a model.

We performed RNA-seq of GC-2spd(ts) cell clones that

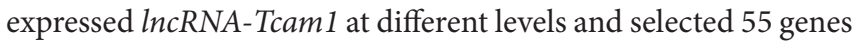
as initial candidates of its targets. Then, we investigated (1) their expression in testes at different developmental stages, (2) their expression in GC-2spd(ts) clones different from those used for RNA-seq, and (3) the response to induction of $\operatorname{lncRNA-Tcam1}$ transcription by the Tet-off system. Eventually, these analyses detected six immune-related genes, Trim30a, Ifit3, Tgtp2, Ifi47,

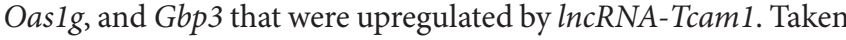



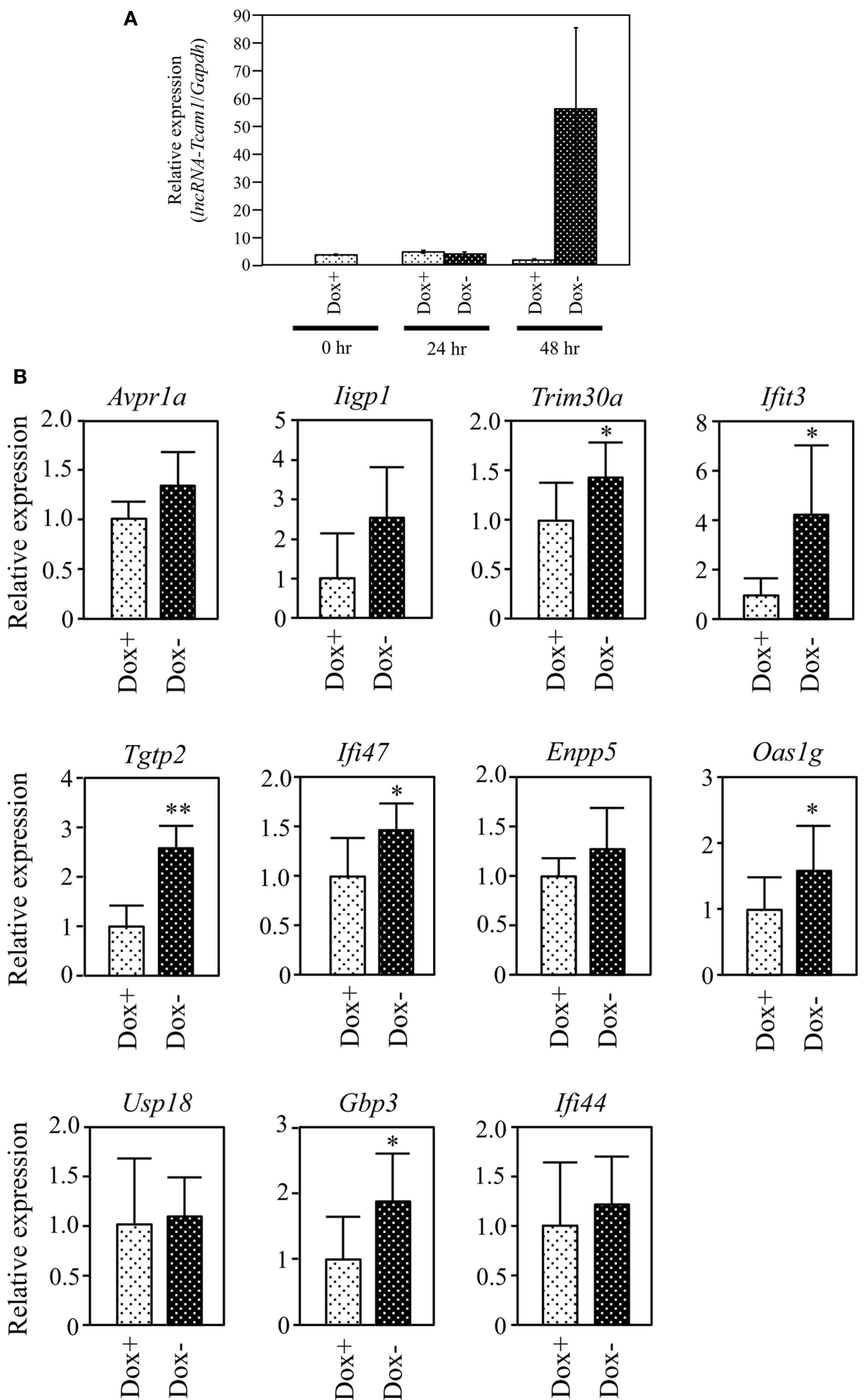

FIGURE 4 | Expression of target gene candidates in response to induction of long non-coding RNA-Tcam1 (IncRNA-Tcam1) transcription by the Tet-off system. (A) Induction of IncRNA-Tcam1 transcription by the Tet-off system. GC-2spd(ts) cells were transfected with the construct for IncRNA-Tcam1 overexpression in response to the doxycycline (Dox) removal. After the selection of successfully transfected cells with puromycin, they were cultured in the presence (Dox+) or absence of Dox (Dox-) for 24 or $48 \mathrm{~h}$. The cells were collected, and quantitative reverse transcription-polymerase chain reaction (qRT-PCR) was performed to measure the IncRNA-Tcam 1 level using Gapdh as an internal control. The data represent the means \pm SD from three independent experiments. A dramatic increase of IncRNA-Tcam 1 transcription was observed in the Dox- sample at $48 \mathrm{~h}$ after the induction. (B) Expression of candidate genes at $48 \mathrm{~h}$ after the induction. qRT-PCR was performed, and the data were normalized to Gapdh. The values from Dox- samples were further normalized to those from Dox+ samples and expressed as fold-increases. The data represents the means \pm SD from five independent experiments. The statistical significance was analyzed by Student's $t$-test. ${ }^{\star} P<0.05,{ }^{\star *} P<0.01$ compared to Dox+ samples. 
TABLE 2 | Genes potentially activated by IncRNA-Tcam1.

\begin{tabular}{|c|c|c|c|c|}
\hline Gene & UCSC-ID & Description & Relation to immune response & Chromosome \\
\hline Trim30a & uc009iwh.1 & Tripartite motif-containing 30A & Negative-feedback regulator & 7 \\
\hline Ifit3 & uc008hgo.1 & Interferon-induced protein with tetratricopeptide repeats 3 & Immune response gene & 19 \\
\hline Tgtp2 & uc007ipp.2 & T cell-specific GTPase 2 & Immune response gene & 11 \\
\hline Ifi47 & uc007ipq. 1 & Interferon gamma inducible protein 47 & Immune response gene & 11 \\
\hline Oas1g & uc008zii.1 & 2'-5' oligoadenylate synthetase $1 \mathrm{G}$ & Immune response gene & 5 \\
\hline Gbp3 & uc008rov. 1 & Guanylate binding protein 3 & Immune response gene & 3 \\
\hline
\end{tabular}

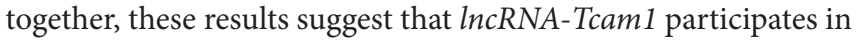
the functional regulation of the mouse testis via upregulation of the six genes during spermatogenesis.

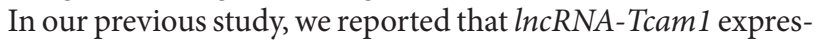
sion was unlikely to be related to the regulation of neighboring genes (38), and our present data support this. Four target genes, Trim30a, Ifit3, Oas1g, and Gbp3, were located on different chro-

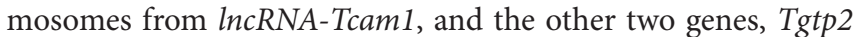
and Ifi47, were at the same locus on chromosome 11 but approximately $57 \mathrm{Mb}$ distant from the lncRNA (Table 2). Therefore, $\ln C R N A-T c a m 1$ does not control its neighboring genes. How this lncRNA activates the six genes is not clear, but the $\operatorname{lncRNA-Tcam} 1$ locus may spatially locate at positions close to its target gene loci

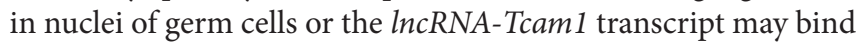
to its target loci in response to immune signals. Additionally, the

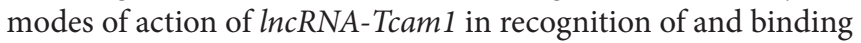
to targets may be similar to those of other lncRNAs related to immune response $(54,55)$. Such studies are currently in progress.

Of particular interest is that the five target genes were immune response genes. Ifit3 and Oas1g have antiviral functions in some tissues including the lung and liver $(56,57)$, and Tgtp2, Ifi47, and $G b p 3$ contributes to defense against bacteria and protozoa (58-60). Interestingly, Ifi47 and Gbp3 were reported to play some roles in defense against Toxoplasma Gondii $(58,60)$, which could impair spermatogenesis by infecting the rat testis (61). In addition, Trim $30 a$ is a negative-feedback regulator of immune response against virus (62). Although their functional roles in the testis remain unknown $(58,60,63)$, these findings suggest

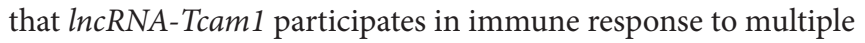
pathogenic microbes by activating these genes during meiosis, and thereby contributes to normal progression of spermatogenesis regulated by the endocrine system.

The physiological significance of some of the target genes in immune defense has been demonstrated by several studies. Interleukin $17 \mathrm{a}$ was elevated by infection of rhinovirus in the lung, and led to upregulation of the Oas $1 g$ gene, which caused the degradation of viral RNAs (64). Dengue virus infection in lung epithelial cells upregulated the Ifit3 gene, which suppressed the virus production (65). In dendritic cells, infection of Listeria monocytogenes increased expression of Tgtp 2 and Oas $1 g$ genes to eventually reduce the bacterial titer (66). All of these indicate that the genes are responsive to various types of infection and contribute to immune defense in vivo, which suggests that they also play important roles in the immune response in the testis.

The testis is an immunoprivileged tissue and has evolved the innate immune system $(67,68)$. The innate immunity involves the interferon response, and key molecules for that are Toll-like receptors (TLRs). Activation of TLRs induces the interferon production and increases expression of interferon-responsive genes (67). Because mouse spermatogonia and primary spermatocytes constitutively express one of the TLR genes, Tlr3, and interferon receptor genes $(69,70)$, TLR3-mediated immune pathway is likely to be active in the testis. Notably, the five immune responsive genes are known to be responsive to interferon, so they may be activated through the TLR 3 pathway in germ cells when the testis is infected by some pathogens. Therefore, $\ln C R N A$-Tcam 1 may regulate some innate immune responses by controlling the interferon-responsive genes during meiosis.

It is now well known that a wide variety of lncRNAs are expressed in the testis $(15,16,71)$, but their functional investigation has just begun. A few studies have thus far indicated biological roles of lncRNAs in self-renewal of spermatogonia (72), regulation of a signaling pathway (73), and progression of meiosis (74) during spermatogenesis. We originally revealed the involvement

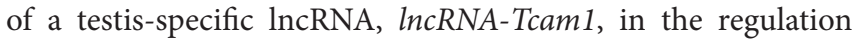
of immune-related genes in mouse spermatocyte-derived cells, and thus, the present study paves the way for investigating novel immune molecular mechanisms underpinning spermatogenesis via the endocrine system.

\section{ETHICS STATEMENT}

Experimental procedures used in this study were approved by the Institutional Animal Use and Care Committee at Hokkaido University.

\section{AUTHOR CONTRIBUTIONS}

MK and AK designed the study. MK, KO, SM, and AS performed the experiments. MK, KO, SM, AS, HS, and AK analyzed the data and wrote the paper.

\section{ACKNOWLEDGMENTS}

The authors thank Dr. Kazuhiro Murakami for kindly gifting pPBhCMV ${ }^{\star} 1$-cHA-pPA, pPBCAGtTA-IN, and pPyCAG-PBase plasmids.

\section{FUNDING}

This work was supported by Grant-in-aid for Scientific Research 15H04317 and Grant-in-aid for JSPS Fellows 24-6230 from Japan Society for the Promotion of Science. 


\section{SUPPLEMENTARY MATERIAL}

The Supplementary Material for this article can be found online at http://www.frontiersin.org/article/10.3389/fendo.2017.00299/ full\#supplementary-material.

FIGURE S1 | Expression of target gene candidates downregulated by IncRNA-Tcam 1 in postnatal testes. Total RNAs were isolated from 7- and 14-day-old mouse testes, and quantitative reverse transcription-polymerase chain reaction (qRT-PCR) was performed for the candidate genes that might be downregulated by IncRNA-Tcam1. All the data were normalized to the value of Aip gene. Gray and light black bars represent the data in 7-and 14-day-old testes, respectively. None of the indicated genes showed inverse correlation to IncRNA-Tcam1.

FIGURE S2 | Expression of target gene candidates upregulated by IncRNATcam1 in postnatal testes. Quantitative reverse transcription-polymerase chain

\section{REFERENCES}

1. Jan SZ, Hamer G, Repping S, de Rooij DG, van Pelt AM, Vormer TL. Molecular control of rodent spermatogenesis. Biochim Biophys Acta (2012) 1822(12):1838-50. doi:10.1016/j.bbadis.2012.02.008

2. Griswold MD. Spermatogenesis: the commitment to meiosis. Physiol Rev (2016) 96(1):1-17. doi:10.1152/physrev.00013.2015

3. Alves MG, Rato L, Carvalho RA, Moreira PI, Socorro S, Oliveira PF. Hormonal control of Sertoli cell metabolism regulates spermatogenesis. Cell Mol Life Sci (2013) 70(5):777-93. doi:10.1007/s00018-012-1079-1

4. Chimento A, Sirianni R, Casaburi I, Pezzi V. Role of estrogen receptors and $\mathrm{g}$ protein-coupled estrogen receptor in regulation of hypothalamus-pituitary-testis axis and spermatogenesis. Front Endocrinol (2014) 5:1. doi:10.3389/ fendo.2014.00001

5. Smith LB, Walker WH. The regulation of spermatogenesis by androgens. Semin Cell Dev Biol (2014) 30:2-13. doi:10.1016/j.semcdb.2014. 02.012

6. Shima JE, McLean DJ, McCarrey JR, Griswold MD. The murine testicular transcriptome: characterizing gene expression in the testis during the progression of spermatogenesis. Biol Reprod (2004) 71(1):319-30. doi:10.1095/ biolreprod.103.026880

7. O’Bryan MK, de Kretser D. Mouse models for genes involved in impaired spermatogenesis. Int J Androl (2006) 29(1):76-89. doi:10.1111/j.13652605.2005.00614.x

8. Roy A, Matzuk MM. Deconstructing mammalian reproduction: using knockouts to define fertility pathways. Reproduction (2006) 131(2):207-19. doi:10.1530/rep.1.00530

9. Brower JV, Lim CH, Jorgensen M, Oh SP, Terada N. Adenine nucleotide translocase 4 deficiency leads to early meiotic arrest of murine male germ cells. Reproduction (2009) 138(3):463-70. doi:10.1530/REP-09-0201

10. Yan W. Male infertility caused by spermiogenic defects: lessons from gene knockouts. Mol Cell Endocrinol (2009) 306(1-2):24-32. doi:10.1016/j. mce.2009.03.003

11. Gaucher J, Boussouar F, Montellier E, Curtet S, Buchou T, Bertrand S, et al. Bromodomain-dependent stage-specific male genome programming by Brdt. ЕМBO J (2012) 31(19):3809-20. doi:10.1038/emboj.2012.233

12. Yoneda R, Takahashi T, Matsui H, Takano N, Hasebe Y, Ogiwara K, et al. Three testis-specific paralogous serine proteases play different roles in murine spermatogenesis and are involved in germ cell survival during meiosis. Biol Reprod (2013) 88(5):118. doi:10.1095/biolreprod.112.106328

13. Wu YY, Yang Y, Xu YD, Yu HL. Targeted disruption of the spermatid-specific gene Spata31 causes male infertility. Mol Reprod Dev (2015) 82(6):432-40. doi:10.1002/mrd.22491

14. Miao H, Miao CX, Li N, Han J. FOXJ2 controls meiosis during spermatogenesis in male mice. Mol Reprod Dev (2016) 83(8):684-91. doi:10.1002/ $\operatorname{mrd} .22671$

15. Necsulea A, Soumillon M, Warnefors M, Liechti A, Daish T, Zeller U, et al. The evolution of lncRNA repertoires and expression patterns in tetrapods. Nature (2014) 505(7485):635-40. doi:10.1038/nature12943 reaction (qRT-PCR) was performed, and the data are shown as in Supplemental Figure S1. None of the indicated genes exhibited positive correlation to IncRNA-Tcam1.

TABLE S1 | Candidate genes initially identified as those suppressed by IncRNATcam1. RNA-sequencing revealed 29 genes that were differentially expressed between GC-2spd-Full and GC-2spd- $\Delta$ prom. UCSC IDs which mapped to the same gene symbol were unified.

TABLE S2 | Candidate genes initially identified as those activated by IncRNATcam1. RNA-sequencing revealed 26 genes that were differentially expressed between GC-2spd-Full and GC-2spd- $\Delta$ prom. UCSC IDs which mapped to the same gene symbol were unified.

TABLE S3 | Ct values of the six final candidate genes that were potentially activated by IncRNA-Tcam 1 in testicular germ cells by quantitative reverse transcription-polymerase chain reaction (qRT-PCR). The value of an internal control (Aip) is also indicated.

16. Washietl S, Kellis M, Garber M. Evolutionary dynamics and tissue specificity of human long noncoding RNAs in six mammals. Genome Res (2014) 24(4):616-28. doi:10.1101/gr.165035.113

17. Lanz RB, McKenna NJ, Onate SA, Albrecht U, Wong J, Tsai SY, et al. A steroid receptor coactivator, SRA, functions as an RNA and is present in an SRC-1 complex. Cell (1999) 97(1):17-27. doi:10.1016/s0092-8674(00)80711-4

18. Li W, Notani D, Ma Q, Tanasa B, Nunez E, Chen AY, et al. Functional roles of enhancer RNAs for oestrogen-dependent transcriptional activation. Nature (2013) 498(7455):516-20. doi:10.1038/nature12210

19. Takayama K, Horie-Inoue K, Katayama S, Suzuki T, Tsutsumi S, Ikeda K, et al. Androgen-responsive long non-coding RNA CTBP1-AS promotes prostate cancer. EMBO J (2013) 32(12):1665-80. doi:10.1038/emboj.2013.99

20. Yang L, Lin C, Jin C, Yang JC, Tanasa B, Li W, et al. lncRNA-dependent mechanisms of androgen-receptor-regulated gene activation programs. Nature (2013) 500(7464):598-602. doi:10.1038/nature12451

21. Zhang A, Zhao JC, Kim J, Fong KW, Yang YA, Chakravarti D, et al. LncRNA HOTAIR enhances the androgen-receptor-mediated transcriptional program and drives castration-resistant prostate cancer. Cell Rep (2015) 13(1):209-21. doi:10.1016/j.celrep.2015.08.069

22. Rinn JL, Chang HY. Genome regulation by long noncoding RNAs. Annu Rev Biochem (2012) 81:145-66. doi:10.1146/annurev-biochem-051410092902

23. Chen LL. Linking long non-coding RNA localization and function. Trends Biochem Sci (2016) 41(9):761-72. doi:10.1016/j.tibs.2016.07.003

24. Dluzen DF, Noren Hooten N, Evans MK. Extracellular RNA in aging. Wiley Interdiscip Rev RNA (2017) 8(2):1385. doi:10.1002/wrna.1385

25. Kim KM, Abdelmohsen K, Mustapic M, Kapogiannis D, Gorospe M. RNA in extracellular vesicles. Wiley Interdiscip Rev RNA (2017) 8(4):1413. doi:10.1002/ wrna. 1413

26. Taylor DH, Chu ET, Spektor R, Soloway PD. Long non-coding RNA regulation of reproduction and development. Mol Reprod Dev (2015) 82(12):932-56. doi:10.1002/mrd.22581

27. Schmitz SU, Grote P, Herrmann BG. Mechanisms of long noncoding RNA function in development and disease. Cell Mol Life Sci (2016) 73(13):2491-509. doi:10.1007/s00018-016-2174-5

28. Dey BM, Mueller AC, Dutta A. Long non-coding RNAs as emerging regulators of differentiation, development, and disease. Transcription (2014) 5(4):e944014. doi:10.4161/21541272.2014.944014

29. Flynn RA, Chang HY. Long noncoding RNAs in cell-fate programming and reprogramming. Cell Stem Cell (2014) 14(6):752-61. doi:10.1016/j. stem.2014.05.014

30. Aune TM, Spurlock CF. Long non-coding RNAs in innate and adaptive immunity. Virus Res (2016) 212:146-60. doi:10.1016/j.virusres.2015.07.003

31. Valadkhan S, Gunawardane LS. IncRNA-mediated regulation of the interferon response. Virus Res (2016) 212:127-36. doi:10.1016/j.virusres.2015. 09.023

32. Zhao XY, Lin JD. Long noncoding RNAs: a new regulatory code in metabolic control. Trends Biochem Sci (2015) 40(10):586-96. doi:10.1016/j. tibs.2015.08.002 
33. Wei S, Du M, Jiang Z, Hausman GJ, Zhang L, Dodson MV. Long noncoding RNAs in regulating adipogenesis: new RNAs shed lights on obesity. Cell Mol Life Sci (2016) 73(10):2079-87. doi:10.1007/s00018-016-2169-2

34. Hirose T, Mishima Y, Tomari Y. Elements and machinery of non-coding RNAs: toward their taxonomy. EMBO Rep (2014) 15(5):489-507. doi:10.1002/ embr.201338390

35. Li W, Notani D, Rosenfeld MG. Enhancers as non-coding RNA transcription units: recent insights and future perspectives. Nat Rev Genet (2016) 17(4):207-23. doi:10.1038/nrg.2016.4

36. Sakatani S, Takahashi R, Okuda Y, Aizawa A, Otsuka A, Komatsu A, et al. Structure, expression, and conserved physical linkage of mouse testicular cell adhesion molecule-1 (TCAM-1) gene. Genome (2000) 43(6):957-62. doi:10.1139/g00-071

37. Nalam RL, Lin YN, Matzuk MM. Testicular cell adhesion molecule 1 (TCAM1) is not essential for fertility. Mol Cell Endocrinol (2010) 315(1-2):246-53. doi:10.1016/j.mce.2009.09.010

38. Kurihara M, Shiraishi A, Satake H, Kimura AP. A conserved noncoding sequence can function as a spermatocyte-specific enhancer and a bidirectional promoter for a ubiquitously expressed gene and a testis-specific long noncoding RNA. J Mol Biol (2014) 426(17):3069-93. doi:10.1016/j.jmb.2014. 06.018

39. Wang H, Wen L, Yuan Q, Sun M, Niu M, He Z. Establishment and applications of male germ cell and Sertoli cell lines. Reproduction (2016) 152(2):R31-40. doi:10.1530/REP-15-0546

40. Hofmann MC, Hess RA, Goldberg E, Millán JL. Immortalized germ cells undergo meiosis in vitro. Proc Natl Acad Sci U S A (1994) 91(12):5533-7. doi:10.1073/pnas.91.12.5533

41. Wolkowicz MJ, Coonrod SA, Reddi PP, Millan JL, Hofmann MC, Herr JC. Refinement of the differentiated phenotype of the spermatogenic cell line GC-2spd(ts). Biol Reprod (1996) 55(4):923-32. doi:10.1095/biolreprod55. 4.923

42. Chandrasekaran Y, McKee CM, Ye Y, Richburg JH. Influence of TRP53 status on FAS membrane localization, CFLAR (c-FLIP) ubiquitinylation, and sensitivity of GC-2spd (ts) cells to undergo FAS-mediated apoptosis. Biol Reprod (2006) 74(3):560-8. doi:10.1095/biolreprod.105.045146

43. Onorato TM, Brown PW, Morris PL. Mono-(2-ethylhexyl) phthalate increases spermatocyte mitochondrial peroxiredoxin 3 and cyclooxygenase 2. J Androl (2008) 29(3):293-303. doi:10.2164/jandrol.107.003335

44. Esakky P, Hansen DA, Drury AM, Moley KH. Modulation of cell cycle progression in the spermatocyte cell line [GC-2spd(ts) Cell-Line] by cigarette smoke condensate (CSC) via arylhydrocarbon receptor-nuclear factor erythroid 2-related factor 2 (Ahr-Nrf2) pathway. Biol Reprod (2014) 90(1):9. doi:10.1095/biolreprod.113.113225

45. Wolfe SA, Wilkerson DC, Prado S, Grimes SR. Regulatory factor X2 (RFX2) binds to the H1t/TE1 promoter element and activates transcription of the testis-specific histone H1t gene. J Cell Biochem (2004) 91(2):375-83. doi:10.1002/ jcb. 10748

46. Grimes SR, Prado S, Wolfe SA. Transcriptional activation of the testis-specific histone H1t gene by RFX2 may require both proximal promoter X-box elements. J Cell Biochem (2005) 94(2):317-26. doi:10.1002/jcb.20320

47. Li W, Wu ZQ, Zhao J, Guo SJ, Li Z, Feng X, et al. Transient protection from heat-stress induced apoptotic stimulation by metastasis-associated protein 1 in pachytene spermatocytes. PLoS One (2011) 6(10):e26013. doi:10.1371/ journal.pone. 0026013

48. Kurihara M, Kimura AP. Characterization of the human TCAM1P pseudogene and its activation by a potential dual promoter-enhancer: comparison with a protein-coding mouse orthologue. FEBS Lett (2015) 589(4):540-7. doi:10.1016/j.febslet.2015.01.023

49. Matsubara S, Takahashi T, Kimura AP. Epigenetic patterns at the mouse prolyl oligopeptidase gene locus suggest the $\mathrm{CpG}$ island in the gene body to be a novel regulator for gene expression. Gene (2010) 465(1-2):17-29. doi:10.1016/j.gene.2010.06.006

50. Murakami K, Günesdogan U, Zylicz JJ, Tang WW, Sengupta R, Kobayashi $\mathrm{T}$, et al. NANOG alone induces germ cells in primed epiblast in vitro by activation of enhancers. Nature (2016) 529(7586):403-7. doi:10.1038/ nature 16480

51. Luk AC, Chan WY, Rennert OM, Lee TL. Long noncoding RNAs in spermatogenesis: insights from recent high-throughput transcriptome studies. Reproduction (2014) 147(5):R131-41. doi:10.1530/REP-13-0594
52. Chalmel F, Lardenois A, Evrard B, Rolland AD, Sallou O, Dumargne MC, et al. High-resolution profiling of novel transcribed regions during rat spermatogenesis. Biol Reprod (2014) 91(1):5. doi:10.1095/biolreprod.114.118166

53. Ran M, Chen B, Li Z, Wu M, Liu X, He C, et al. Systematic identification of long noncoding RNAs in immature and mature porcine testes. Biol Reprod (2016) 94(4):77. doi:10.1095/biolreprod.115.136911

54. Carpenter S, Aiello D, Atianand MK, Ricci EP, Gandhi P, Hall LL, et al. A long noncoding RNA mediates both activation and repression of immune response genes. Science (2013) 341(6147):789-92. doi:10.1126/science.1240925

55. Nishitsuji H, Ujino S, Yoshio S, Sugiyama M, Mizokami M, Kanto T, et al. Long noncoding RNA \#32 contributes to antiviral responses by controlling interferon-stimulated gene expression. Proc Natl Acad Sci U S A (2016) 113(37):10388-93. doi:10.1073/pnas.1525022113

56. Fensterl V, Sen GC. Interferon-induced Ifit proteins: their role in viral pathogenesis. J Virol (2015) 89(5):2462-8. doi:10.1128/JVI.02744-14

57. ElkhateebE, Tag-El-Din-Hassan HT, SasakiN, TorigoeD, Morimatsu M, AguiT. The role of mouse 2',5'-oligoadenylate synthetase 1 paralogs. Infect Genet Evol (2016) 45:393-401. doi:10.1016/j.meegid.2016.09.018

58. Collazo CM, Yap GS, Sempowski GD, Lusby KC, Tessarollo L, Vande Woude GF, et al. Inactivation of LRG-47 and IRG-47 reveals a family of interferon $\gamma$-inducible genes with essential, pathogen-specific roles in resistance to infection. J Exp Med (2001) 194(2):181-7. doi:10.1084/jem.194.2.181

59. Rodríguez-Contreras D, de IT, Velasco J, Shoemaker CB, Laclette JP. The Taenia solium glucose transporters TGTP1 and TGTP2 are not immunologically recognized by cysticercotic humans and swine. Parasitol Res (2002) 88(3):280-2. doi:10.1007/s00436-001-0528-9

60. Yamamoto M, Okuyama M, Ma JS, Kimura T, Kamiyama N, Saiga H, et al. A cluster of interferon- $\gamma$-inducible p65 GTPases plays a critical role in host defense against Toxoplasma gondii. Immunity (2012) 37(2):302-13. doi:10.1016/j.immuni.2012.06.009

61. Terpsidis KI, Papazahariadou MG, Taitzoglou IA, Papaioannou NG, Georgiadis MP, Theodoridis IT. Toxoplasma gondii: reproductive parameters in experimentally infected male rats. Exp Parasitol (2009) 121(3):238-41. doi:10.1016/j.exppara.2008.11.006

62. Wang Y, Lian Q, Yang B, Yan S, Zhou H, He L, et al. TRIM30 $\alpha$ is a negative-feedback regulator of the intracellular DNA and DNA virus-triggered response by targeting STING. PLoS Pathog (2015) 11(6):e1005012. doi:10.1371/journal. ppat. 1005012

63. Choi UY, Hur JY, Lee MS, Zhang Q, Choi WY, Kim LK, et al. Tripartite motif-containing protein 30 modulates TCR-activated proliferation and effector functions in CD4+ T cells. PLoS One (2014) 9(4):e95805. doi:10.1371/ journal.pone.0095805

64. Graser A, Ekici AB, Sopel N, Melichar VO, Zimmermann T, Papadopoulos NG, et al. Rhinovirus inhibits IL-17A and the downstream immune responses in allergic asthma. Mucosal Immunol (2016) 9(5):1183-92. doi:10.1038/mi.2015.130

65. Hsu YL, Shi SF, Wu WL, Ho LJ, Lai JH. Protective roles of interferon-induced protein with tetratricopeptide repeats 3 (IFIT3) in dengue virus infection of human lung epithelial cells. PLoS One (2013) 8(11):e79518. doi:10.1371/ journal.pone.0079518

66. Pontiroli F, Dussurget O, Zanoni I, Urbano M, Beretta O, Granucci F, et al. The timing of IFN $\beta$ production affects early innate responses to Listeria monocytogenes and determines the overall outcome of lethal infection. PLoS One (2012) 7(8):e43455. doi:10.1371/journal.pone.0043455

67. Chen Q, Deng T, Han D. Testicular immunoregulation and spermatogenesis. Semin Cell Dev Biol (2016) 59:157-65. doi:10.1016/j.semcdb.2016.01.019

68. Fijak M, Meinhardt A. The testis in immune privilege. Immunol Rev (2006) 213:66-81. doi:10.1111/j.1600-065X.2006.00438.x

69. Wang T, Zhang X, Chen Q, Deng T, Zhang Y, Li N, et al. Toll-like receptor 3 -initiated antiviral responses in mouse male germ cells in vitro. Biol Reprod (2012) 86(4):106. doi:10.1095/biolreprod.111.096719

70. Satie AP, Mazaud-Guittot S, Seif I, Mahé D, He Z, Jouve G, et al. Excess type I interferon signaling in the mouse seminiferous tubules leads to germ cell loss and sterility. J Biol Chem (2011) 286(26):23280-95. doi:10.1074/jbc. M111.229120

71. Yoneda R, Satoh Y, Yoshida I, Kawamura S, Kotani T, Kimura AP. A genomic region transcribed into a long noncoding RNA interacts with the Prss42/Tessp-2 promoter in spermatocytes during mouse spermatogenesis, and its flanking sequences can function as enhancers. Mol Reprod Dev (2016) 83:541-57. doi:10.1002/mrd.22650 
72. Li L, Wang M, Wu X, Geng L, Xue Y, Wei X, et al. A long non-coding RNA interacts with Gfral and maintains survival of mouse spermatogonial stem cells. Cell Death Dis (2016) 7:e2140. doi:10.1038/cddis.2016.24

73. Arun G, Akhade VS, Donakonda S, Rao MR. mrhl RNA, a long noncoding RNA, negatively regulates Wnt signaling through its protein partner Ddx5/ p68 in mouse spermatogonial cells. Mol Cell Biol (2012) 32(15):3140-52. doi:10.1128/MCB.00006-12

74. Anguera MC, Ma W, Clift D, Namekawa S, Kelleher RJ, Lee JT. Tsx produces a long noncoding RNA and has general functions in the germline, stem cells, and brain. PLoS Genet (2011) 7(9):e1002248. doi:10.1371/journal.pgen. 1002248
Conflict of Interest Statement: The authors declare that the research was conducted in the absence of any commercial or financial relationships that could be construed as a potential conflict of interest.

Copyright (c) 2017 Kurihara, Otsuka, Matsubara, Shiraishi, Satake and Kimura. This is an open-access article distributed under the terms of the Creative Commons Attribution License (CC BY). The use, distribution or reproduction in other forums is permitted, provided the original author(s) or licensor are credited and that the original publication in this journal is cited, in accordance with accepted academic practice. No use, distribution or reproduction is permitted which does not comply with these terms. 